\title{
Breath Holding Spasms - a clinical review
}

\author{
Dinesh Saroj
}

Neurodevelopmental Paediatrician, Fellowship in Learning Disabilities and Neurodevelopmental Paediatrics, Lokmanya Tilak Municipal Medical College and General Hospital, Mumbai

Corresponding author: Dinesh Saroj

Email -dnshsaroj@gmail.com

\begin{abstract}
Breath holding spasms are common psychological problems seen in children and may serve as a marker for stubbornness and anger. There are no clear clinical guidelines for the management of breath holding spasms whereas a medical and psychological approach works best in both cases. The present paper is a clinical review on breath holding spasms for psychiatrists and serves as an overview of the topic. Various medical and non medical interventions are also discussed along with management.
\end{abstract}

Keywords: breath holding spasms, children, child psychiatry, tantrums.

(Paper received $-30^{\text {th }}$ April 2019, Peer review completed $-2^{\text {nd }}$ October 2019)

(Accepted $-12^{\text {th }}$ October 2019)

\section{INTRODUCTION}

Breath holding spells (BHS) are common nonepileptic paroxysmal events. They are brief periods when young children stop breathing for less than 1 minute. These spells occur commonly during the initial years of life and are considered to be age related expressions of frustration, anger, pain or fear. The term appears to be a misnomer, as episodes are mostly involuntary, occurring during expiration. The spell is a reflex; children don't have breath-holding spells on purpose.

\section{EPIDEMIOLOGY}

Breath holding spells occur between 6 to 18 months of age affecting $4 \%$ - 5\% of the pediatric population. Most commonly, the spells begin during infancy; almost always before 2 years of age with a male to female ratio of 3:1. The onset may occur in the first few weeks of life, with up to $15 \%$ of children having onset of spells at less than 6 months of age. Onset after 2 years is seen in less than $10 \%$ cases. Approximately, $50 \%$ of children experience resolution by 4 years of age and almost all children outgrow those spells around the age of 6 years. In rare cases, the spells persist beyond 8 years. The frequency might range anything from altogether infrequent to multiple episodes a day. It is rare to see breath-holding spells in the first 6 months of life and in the neonatal period. $23 \%$ to $38 \%$ of these children tend to have positive family history indicating a genetic predisposition. Autosomal dominant pattern with reduced penetrance is the inheritance pattern seen in this condition based on a regression model for pedigree analysis.

\section{TYPES OF BREATH HOLDING SPASMS}

There are three subtypes of breath holding spells that include- cyanotic, pallid, or mixed episodes. Cyanotic episodes are more predominant and commonly seen in $54-62 \%$ of cases, whereas pallid and mixed types are seen in about $19-24 \%$ each. 


\section{CLINICAL PRESENTATION}

Breath-holding spells are a frightening experience for both parents \& children that require immediate attention and intervention. These involuntary (reflexive) events result in the child becoming apneic at endexpiration. Typically, these episodes are seen in response to a provoking event that makes the child cry anger, minor injury or fear. Crying and pain are the common triggering factors $(84 \%)$ that make the child look pale or cyanosed. At this point, the spell might resolve with a deep breathe (and the condition is termed as Simple BHS). In some cases, it might continue and the child may lose consciousness and fall to the ground. Occasionally, the child may throw seizures followed by a brief period of drowsiness. Unexpected triggers are known to evoke either a cyanotic breath holding spell characterized by crying and holding his or her breath, followed by a brief loss of consciousness with loss of muscle tone, pallor and then cyanosis and a very brief tonic- clonic seizure; or a pallid breath holding spell wherein the child becomes hypertonic with opisthotonus followed occasionally by clonic seizure like movements. Pallid spells may be similar to vasovagal related syncopal events in older children. A few individuals might suffer from frequent, severe pallid BHSs and anoxic seizures. On rare instance, these episodes continue and are followed by vasovagal attacks. These episodes tend to have a strong influence on the lifestyle of both child and his or her family. It may occur in children with age appropriate cognitive development without any subsequent adverse influence on child development.

\section{PATHOPHYSIOLOGY OF BREATH HOLDING SPASMS}

The mechanism behind occurrence of these spells is not clearly evident although autonomic dysregulation, especially sympathetic over-activity has been proposed in cyanotic spells that causes inhibition of respiratory effort and abnormalities in pulmonary reflexes leading to ventilation perfusion mismatches that cause cyanosis. Likewise, overactive vagal response (parasympathetic over-activity leading to bradycardia or brief asystole is implicated phenomenon in children with pallid BHS. These children may show increased propensity for having episodes of vasovagal syncope as adolescents or adults. Thus, two distinct manifestations of BHS reflect variation in autonomic regulation rather than different disease entities. Thus, mechanism of BHS seems to be multi-factorial. Iron deficiency assessed by low serum ferritin seems to be an additional factor contributing to the etiology whereas role of serum zinc levels in causation of BHS is not well established. Studies have suggested a role of zinc deficiency in association with iron deficiencyand not zinc alone in the pathogenesis of BHS.

\section{DIFFERENTIAL DIAGNOSIS}

A detailed history and examination are important for diagnosis making and for differentiating them from epileptic seizures and other causes of syncope. The differential diagnosis of BHS includes seizures, cardiac arrhythmias, dysautonomia and a brainstem tumor or malformation (e.g. Arnold-Chiari malformation) and central nervous system lesions. Iron deficiency with or without anemia may increase the frequency of BHS and some children respond to treatment with ferrous sulfate $(5 \mathrm{mg} / \mathrm{kg}$ per day). Increased frequency has also been observed in children with familial dysautonomia and Rett Syndrome but not as a sole manifestation of these disorders. Rarely, sudden death, prolonged asystole and status epilepticus have been reported in the literature of breath holding spells seen in children.

\section{INVESTIGATIONS}

Children with BHS should have hemoglobin and iron tests/studies performed. Usually, the presence of a provoking event and that of color change before the loss of consciousness allows one to distinguish clinically BHS from seizures however, electro encephalography is occasionally of help. On the other hand, 
occurrence of pallid spells accompanied with loss of consciousness validates an electrocardiogram to evaluate the child for conditions associated with cardiac arrhythmias, such as long QT syndrome. In children who do not present with frequent episodes, a cardiac event monitor instead of a 24-hours ECG monitor may be more useful in recording an ECG during a BHS. In infants, the possibility of gastrooesophageal reflux resulting in apnea should be entertained. In very rare cases, breath-holding spells have been associated with brain stem dysfunction caused by tumors or Arnold-Chiari malformations. In cases where suspected arrhythmias with severe cardiac or neurologic sequela cannot be diagnosed properly through non-invasive methods, an implantation of a cardiac monitor should be considered as part of the diagnostic process.

\section{TREATMENT}

Although BHS are benign, they are often intimidating to parents. The first key to management of breathholding spells includes educating parents how to intercede before the episode progresses and the child becomes highly distressed. It involves demystification and assurance that the spells will not harm the child. Even when child loses consciousness, he or she will resume breathing without any intervention. Parents need to intervene early in defiant behaviour by calmly placing the child in timeout for a period approximating $1 \mathrm{~min}$ for each year of age. Out of fear, parents tend to unnecessarily restrict some activities, may provide attention in response to tantrums or may have difficulty setting consistent limits for the child. This behavior may reinforce the tantrums, impose oppositional behavior or the child may learn to trigger such episode so as to get the desired response from his or her parents. Hence, parents should be alerted that these spells should not prevent them in setting \& enforcing the limits, even if these might provoke the spells. Intensity of the child's own anger and the reciprocal feelings they arouse in their parents might frighten them. Hence, instead of getting aggressive, parents should help their children internalize the controls they want their children to exhibit.

Calmly attempting to avert defiance by suggesting children simple choices can help arouse a sense of selfcontrol and autonomy and reduce the child's feelings of anger and shame, thereby altering the possibility of reinforcing oppositional behavior and the resultant adverse consequences on social and emotional development. This can be explained to the child, once he or she is calm, that the reasons for frustration are understandable and acceptable but defiance is not. Physician must assess how parents manage their anger before making any further recommendations about handling the child. It is also important to assure parents that there is no increased propensity for acquiring seizure disorders in children who have had one during a breath holding spell.

Referral to mental health evaluation is indicated only when it does not respond to the parent's coaching or is accompanied by head banging or high levels of aggression. Without sufficient reinforcement behaviour, breath holding generally disappears. Also, proper psychotherapy consultation with the parents, especially mothers, can help prevent these spells to a large extent.

\section{Medications}

Definitive therapy has not been recommended for breath holding spells in children although many studies have explored different treatments. Anticholinergic drugs like Atropine and Scopolamine have been recommended to antagonize vagal hyperactivity and subsequent cardiac inhibition; these are particularly beneficial in decreasing the frequency of associated seizures in cases of pallid BHS. Theophylline is employed for its ability to stimulate the medullary respiratory center and for its positive chronotropic effects; Piracetam finds its role in hyperactive children with BHS. Clonidine and Tetrabenazine have been proposed in cyanotic BHS while those who suffer from repeated episodes, a line of medications is indicated including Piracetam, Glycopyrrolate and Theophylline which have been shown to have good results. Accordingly, in children with severe pallid BHSs, oral treatment with glycopyrrolate and theophylline is indicated as an alternative therapy. Children with severe and frequent spells associated with asystole or severe bradycardia and anoxic seizures benefit the most by ventricular pacemaker implantation. 


\section{Iron Supplements}

Role of iron supplements in children with BHS without anemia is unclear. Research has found that iron is effective in decreasing BHS even in some of those children who were not iron deficient. The mechanism by which iron decreases BHS is not fully understood, but it may improve some aspects of the autonomic dysregulation. In children with iron deficiency anemia, disruption in the catecholamine mechanism owing to the autonomic dysregulation leads to cardiac rhythm and respiratory disturbances and it can be improved by iron supplementation. Treatment with iron has been reported to decrease the frequency of BHS in anemic as well as non-anemic children.

\section{Piracetam}

Piracetam (2-oxo-1-pyrrolidine) is a cyclic derivative of gamma-amino-butyric acid (GABA) obtained after the loss of one molecule of water followed by ring formation. Its indications include various cognitive disorders and BHS in children. Piracetam increases tissue oxygenation and the inhibitory process of tissue hyper polarization similar to GABA, thereby controlling the breath holding spells. A gradual and significant improvement was noticed after two to three months of administering Piracetam in terms of reduction in the number of attacks/month. Research has also reported significant decline in spells frequency after continuing Piracetam for 2 months and concluded that the drug is safe and effective. Many other studies have proven more than $90 \%$ efficacy of Piracetam over placebo. None of the studies reported any serious adverse effects of Piracetam except emotional lability, vomiting and allergic dermatitis were reported occasionally. Parental reassurance and education are sufficient in Simple BHS but Piracetam $(40 \mathrm{mg} / \mathrm{kg} /$ day) as a prophylaxis is indicated in children with severe and repeated BHS.

\section{Pacemakers}

Studies show that pacemaker implantation, currently a safe procedure in small children, successfully reduced the severity and even resolved the symptoms in rare patients experiencing pallid spells with proven significant bradycardia during the events. The implantable devices are small and can be removed if necessary.

\section{CONCLUSION}

In summary, breath holding spells occur commonly in childhood, rarely being life threatening. Iron deficiency anemia seems to be an important risk factor in the development of breath-holding spells. Parental education and reassurance remain the mainstay of management. Iron therapy, Piracetam and other medications have shown to be beneficial. In severe forms, specially associated with prolonged asystole or seizures, pharmacological and even surgical measures are indicated. Pacing is a successful option that should be proposed to parents in severe pallid BHS with syncope and prolonged asystole.

\section{RECOMMENDED READING}

1. Abbaskhanian A, Ehteshami S, Sajjadi S, Rezai MS. Effects of Piracetam on Pediatric Breath Holding Spells: A Randomized Double Blind Controlled Trial. Iran J Child Neurol Autumn 2012; 6(4): 9-15.

2. Ahmad Bhat M, Ali W, Mohidin K, Sultana M. Prospective study of severe breath holding spells and role of iron. J Pediatr Neurol. 2007; 5(1):27-32.

3. Anas NG, McBride JT, Boettrich C. Ventilatory chemo-sensitivity in subjects with a history of childhood cyanotic breath-holding spells. Pediatrics 1985;75:76-9

4. Anil B, Nedunchezian K, Jayanthini V, et al. Breath-holding spells: evaluation of autonomic nervous system function. Indian Pediatr.2005; 42:923-927.

5. Azam M, Bhatti N, Shahab N. Piracetam in severe breath holding spells. Int J Pschyiatry Med. 2008; 38(2):195-201.

6. Bhatia MS, Singhal PK, Dhar NK, Nigam VR, Malik SC, Mullick DN. Breath holding spells: an analysis of 50 cases. Indian Pediatr 1990;27(10):1073-9.

7. Blum NJ. Repetitive Behaviors and Tics. In: Carey, Crocker, Coleman, Elias, Feldman, editors, Developmental - Behavioral Pediatrics. 4 th edition. Philadelphia: Saunders; 2009.p. 629-642. 
8. Breukels MA, Plotz FB, Nieuwenhuizen OV, Van Diemen-Steenvoorde J. Breath holding spells in a 3dayold neonate: an unusual early presentation in a family with a history of breath holding spells. Neuropediatrics 2002;33(1):41-2.

9. Carano N, Bo I, Zanetti E, Tchana B, Barbato G, Agnetti A. Glycopyrrolate and theophylline for the treatment of severe pallid breath-holding spells. Pediatrics 2013;131(4):e1280-3

10. Colina KF, Abelson HT. Resolution of breath-holding spells with treatment of concomitant anemia. J Pediatr 1995;126:395-7.

11. Daoud AS, Batieha A, Al-Sheyyab M, et al: Effectiveness of iron therapy on breath-holding spells. J Pediatr 1997;130:547-550.

12. Di Lanni M, Wilsher CR, Blank MS, Conners CK, Chase $\mathrm{CH}$, Funkenstein HH. The effects of piracetam in children with dyslexia. J Clin Psychopharmacol. 1985;5(5):272-8.

13. DiMario FJ. Breath-holding spells in childhood. Am J Dis Child 1992;146(1):125-31.

14. DiMario F J Jr. Prospective study of children with cyanotic and pallid breath-holding spells. Pediatrics 2001;107(2):265-9.

15. DiMario FJ Jr .Increased QT dispersion in breath-holding spells. Acta Paediatr 2004:93:728-30.

16. DiMario F J, Sarfarazi M. Family pedigree analysis of children with severe breath-holding spells. J Pediatr 1997;130(4):647-51.

17. Dimario FJ. Breath-holding spells in childhood. Curr Probl Pediatr 1999;29:281-99.

18. Donma MM. Clinical efficacy of piracetam in treatment of breath holding spells. Pediatr Neurol 1998; 18(1):41-5.

19. Emery ES. Status epilepticus secondary to breath-holding and pallid syncopal spells. Neurology 1990;40(5):859.

20. Garg RK. Piracetam for the treatment of breath holding spells. Indian Pediatr1998;35(10):1034-5.

21. Gencgonul H, Cin S, Akar N. Iron and zinc levels in breath holding spells. J Ankara Med School 2002; 21:99-104.

22. Ghai OP, Gupta P, Paul VK. Essential Pediatrics, 6th Ed, Mehta publishers, New Delhi, 2004, pg 55.

23. Goldman RD. Breath-holding spells in infants. Can Fam Physician 2005;61(2):149-50.

24. Moseley L R, Walter H J, DeMaso D R. Age-Specific Behavioral Disturbances. In: Kliegman, Behrman, Jenson, editors, Nelson Textbook of Pediatrics. 20 th edition vol.1 New Delhi: Elsevier; 2016. p. 170-175.

25. Obeid M, Mikati MA. Expanding spectrum of paroxysmal events inchildren: potential mimickers of epilepsy. Pediatr Neurol 2007;37:309-16.

$* * * * * * * * * * * * * * * * * * * * * * * * * * * * *$

Acknowledgements - Nil

Source of Funding - Nil

Conflict of Interest - Nil 